\title{
Meconium stained amniotic fluid: A correlation with mode of delivery and perinatal outcome
}

\author{
Pranoy Nath \\ Correspondence: Dr Pranoy Nath, Associate Professor, Department of Obstetrics and \\ Gynaecology, Silchar Medical College, Silchar, Assam, India; Email - drnathdas@gmail.com \\ Distributed under Creative Commons Attribution-Share Alike 4.0 International.
}

\begin{abstract}
Objectives: The aims of the study were to observe the modes of delivery and fetal outcome in meconium stain liquor. Methodology: This prospective observational study was done from June 2015 to June 2016 . All the pregnant women more than 37 weeks of gestation, with singleton pregnancies, getting admitted in the labour room with meconium stain liquor were included in the study. Results: Among 240 patients of meconium stain liquor, 122 patients had normal vaginal delivery, 15 patients had instrumental delivery and 103 patients were taken up for emergency lower segment caesarean section. Out of 240 newborns, two died in NICU. Hundred three (103) babies were admitted in NICU. Hundred thirty five (135) babies were healthy and were handed over to the mother. Conclusion: Meconium stain amniotic fluid was associated with higher rate of caesarean delivery and increased rate of NICU admission due to birth asphyxia.
\end{abstract}

Keywords: Meconium stain liquor, fetal outcome.

The basic aim of obstetrics is a healthy baby and a healthy mother. For this goal to be achieved, early signs of fetal distress should be recognised as early as possible. The classical signs of fetal hypoxia are decreased fetal movements, variations in the heart rate patterns, presence of meconium in amniotic fluid, decrease in fetal scalp blood $\mathrm{pH}$, etc. The significance of meconium in amniotic fluid as a sign of fetal distress is controversial. There are various theories ascribing it to different mechanisms. The pathological explanation proposes that foetuses pass meconium in response to fetal hypoxia ${ }^{1}$. In utero passage of meconium represents a normal gastrointestinal maturation, which is under neural control ${ }^{2}$. Meconium passage occurs following relaxation of vagal stimulation ${ }^{3}$. At the other end of the spectrum, meconium passage is a normal physiological event in a term fetus and is not a sign of fetal distress in the absence of fetal heart rate abnormality 4, 5. Since all foetuses with meconium passage do not have adverse outcome, it is important to distinguish those who need prompt intervention to prevent meconium aspiration syndrome.

\section{Methods}

This prospective observational study had been done for a period of one year from June 2015 to June 2016, in Silchar Medical College and Hospital, a tertiary centre in southern Assam. The study population included all cases of meconium stained liquor during labour that fulfilled inclusion criteria.

The inclusion criteria were in women in labour with -

1. Term pregnancy ( $>37$ wks of gestation )

Received: 12 th April 2017. Accepted: 3 rd May 2017.

Nath P. Meconium stained amniotic fluid: A correlation with mode of delivery and perinatal outcome. The New Indian Journal of OBGYN. 2018; 4(2): $158-60$. 
2. Cephalic presentation

3. Live singleton normal pregnancy

Exclusion criteria were-

1. Pregnant women in labour with not knowing last menstrual date

2. Eclampsia

3. Antepartum haemorrhage

4. Intrauterine foetal death

5. Congenital malformation

6. Pre-existing maternal heart and lung disease

7. Intra uterine growth restriction

8. Abnormal presentation

A detailed history, general examination and routine blood investigations were done. Mode of delivery in terms of caesarean section, spontaneous vaginal delivery or instrumental delivery was noted. Newborn was followed up till discharge from the hospital. APGAR score, whether the baby needed NICU (Neonatal Intensive Care Unit) admission and other complications were noted. Analysis of the data obtained was done.

\section{Results}

Total number of patients with no prior caesarean deliveries or any other compounding factors leading to

Table 1: Showing fetal status, modes of delivery

\begin{tabular}{lll}
\hline Categories & Number (\%) \\
\hline Fetal & NICU admission & $103(42.9)$ \\
status & Neonatal death & $2(0.8 \%)$ \\
& Healthy babies & $135(56.2 \%)$ \\
& Total & $240(100 \%)$ \\
Modes of & Spontaneous vaginal delivery & $122(50.8 \%)$ \\
delivery & Instrumental delivery & $15(6.25 \%)$ \\
& LSCS & $103(42.9 \%)$ \\
& Total & $240(100 \%)$ \\
\hline
\end{tabular}

caesarean section was 1,846 . Out of which 240 patients had meconium staining of amniotic fluid.

Fetal outcome was measured in terms of morbidity and NICU stay and mortality. Out of 240 newborns, two died in NICU. Hundred three (103) babies were admitted in NICU. Hundred thirty five (135) babies were healthy and were handed over to the mother. Among 240 patients, 122 patients had normal vaginal delivery, 15 patients had instrumental delivery and 103 patients were taken up for emergency lower segment caesarean section (Table 1). Discussion
MSAF (meconium stain amniotic fluid) has been implicated as a factor influencing fetal wellbeing during intrapartum and postpartum periods. Meconium passage prior to birth occurs in up to $20 \%$ of term deliveries, meaning that the frequency of MSAF was one for every five deliveries, thereby making it a very common finding. But, in spite of it being so common, it can really disturb an obstetrician, as it is a very frequent cause of poor foetal outcomes and as it increases the number of neonatal intensive care unit admissions. Presence of meconium in cephalic presentations is considered to be an ominous sign. Meconium staining of amniotic fluid calls for a close vigilance and proper monitoring of labour.

Saunders et al. ${ }^{6}$ reported that caesarean sections were performed twice as frequently in subjects with meconium stained amniotic fluid. This higher rate may be due to lack of facilities such as, foetal scalp $\mathrm{pH}$ monitoring and tracings of foetal electronic monitoring. In accordance with their study results, this study also showed higher caesarean section rates. The current study had a caesarean rate of around $42.9 \%$. Such higher rates partly reflect the abnormal foetal heart rate patterns associated with MSAF and they partly reflect the obstetricians' dilemma in managing such labour, as at this time, they become more concerned about the foetuses and any minute alterations in normal labour patterns end up in caesarean sections. In contrast to this study, Wong $\mathrm{SF}^{7}$ found that $13.2 \%$ of MSAF had undergone caesarean sections as compared to $8.8 \%$ cases who had undergone them in clear amniotic fluid. Such lower rates of caesarean section could be due to incorporation of scalp $\mathrm{pH}$ sampling in their study, unlike ours. Naveen $\mathrm{S}$ et al. $^{8}$ also reported a caesarean section rate of $49.1 \%$ in MSAF.

In this study, $56.2 \%$ infants were asymptomatic at birth, $42.9 \%$ had NICU admission and $0.8 \%$ had death in NICU. Patil et al., ${ }^{9}$ reported that $19 \%$ babies with MSAF had unsatisfactory Apgar scores. The perinatal outcome was poor with MSAF, as was noted in this study, with NICU admissions of $42.9 \%$. Meconium aspiration was the cause of death in around 2 cases.

\section{Conclusion}

Meconium stained amniotic fluid is really worrisome from both, obstetrician's and paediatrician's points of view, as it increases the caesarean rates, causes birth asphyxia, MAS and increases neonatal intensive care unit 
The New Indian Journal of OBGYN. 2018 (January-June); 4(2)

admissions. Presence of MSAF requires intensive foetal monitoring, so as to decrease perinatal morbidity and mortality.

Conflict of interest: None. Disclaimer: Nil.

\section{References}

1.Walker J. Fetal anoxia. J Obstet Gynaecol Br Commonw. 1953; 61: $162-80$.

2.Mathews TG, Warsha WJB. Relevance of the gestational age distribution of meconium passage in utero. Pediatrics. 1979. 64: 30 .

3.Hon EH, Bradfield AH, Hess OW. The electronic evaluation of the fetal heart rate. Am J Obstet Gynecol. 1961; 82: 291 - 300.

4.Fenton AN, Steer CM. Meconium in utero, a sign of fetal maturity. Am J Obstet Gynecol 1962; 83: 354 - 59.

5.Katz LV, Bowes WA Jr. Meconium aspiration syndrome, reflection on a musky subject. Am J Obstet Gynecol. 1992; 166 (1 Pt 1): 171-83.
6.Saunders K. Should we worry about meconium? A controlled study of neonatal outcome. Trop Doct. 2002; 32(1): 7-10.

7.Wong SF, Chow KM, Ho LC. The relative risk of fetal distress in pregnancy associated with meconium-stained liquor at different gestation. Journal of Obstetrics and Gynecol. 2002; 22(6): 594-99.

8.Naveen S, Kumar SV, Ritu S, Kushia P. Predictors of meconium stained amniotic fluid: a possible strategy to reduce neonatal morbidity and mortality. J Obstet Gynecol India. 2006; 56: 514-7.

9.Patil KP, Swamy MK, Samatha K. A one year cross sectional study of management practices of meconium stained amniotic fluid and perinatal outcome. Obstet Gynecol India. 2006; 56: 128-30.

\section{Pranoy Nath ${ }^{1}$}

${ }^{1}$ Associate Professor, Department of Obstetrics and Gynaecology, Silchar Medical College, Silchar, Assam, India 